\title{
Data Safety and Ethical Challenges in Teaching Institution: The AMDI Experience
}

\author{
Dr Muhamad Yusri Musa, Salmiza Zakaria, Siti Meszaida Mohd Ehsan
}

Advanced Medical and Dental Institute (AMDI), Universiti Sains Malaysia, Bertam Kepala Batas, Pulau Pinang

\begin{abstract}
The development of the internet and expansion of digital technology has played massive role in the innovation and utilization of Health Information System (HIS) which refers to a system designed to manage healthcare data. This includes systems that collect, store, manage and transmit a patient's electronic medical record (EMR), hospital management or medical support services and healthcare policies. The rapidly evolving digital technology and internet speed might also increase the risk of cybersecurity threats, genuine risk of patient's data breach, confidentiality related issues and numerous technical challenges. Both users and managers of the system must be aware and properly trained to minimize the risks. Teaching and training institutions have added risk of having multiple batches of students with full or limited access to HIS as part of teaching and training requirements. Rapid turnover of students and clinical trainees pose a significant challenge to the IT managers in controlling and monitoring access to HIS. Additionally, the access to database has become easier for research and audits but may subconsciously led to confidentiality breach and ethical misconduct. There are 4 main components of data safety in HIS namely, data management, data integration, responsibility and accessibility. The potential risks, solutions and future challenges related to data safety and ethical issues are discussed in this presentation as well as review of the Islamic medical ethics concept as true guidance in dealing with ethical misconduct.
\end{abstract}

